\title{
A case report of isolated primary herpes-simplex virus neuroretinitis in an immunocompetent adult
}

\author{
Víctor Lázaro-Rodríguez ${ }^{1,2}$, Halima Berrada ${ }^{1,2^{*}}$ (1) and María José Capella $a^{1,2}$
}

\begin{abstract}
Background: Herpes simplex virus (specifically HSV-1 and HSV-2) are greatly prevalent viruses that can cause conjunctivitis, keratitis and other rarer ocular disorders such as acute retinal necrosis syndrome or neuroretinitis. We report a case of an isolated unilateral neuroretinitis with primary HSV infection in an immunocompetent adult without other related clinical features.

Case presentation: A 60-year-old immunocompetent woman presented with sudden painless central vision loss in her left eye (best corrected visual acuity was 20/200) showing optic disc edema, submacular fluid and a delayed development of a macular star. The macular optical coherence tomography (OCT) showed a serous retinal detachment. Arterial hypertension or exposure to ionizing radiation were ruled out and the microbiological blood test battery was only positive for immunoglobulin M (IgM) for HSV-1 which allowed etiological treatment with oral valacyclovir. Complete resolution and good visual results were found within 3 months.

Conclusions: The present case of isolated neuroretinitis as a primary HSV infection in an immunocompetent patient was resolved with good functional results after valacyclovir treatment. Presence of HSV IgM in absence of other laboratory results could be enough evidence to start HSV treatment in immunocompetent patients with a macular star, as an isolated lesion, after ruling out other non-infectious causes, such as arterial hypertension or exposure to ionizing radiation. Rare infectious agents in immunocompetent patients must be considered in the differential diagnosis of neuroretinitis, even if there are no other typical symptoms or signs that could suggest the disease.
\end{abstract}

Keywords: Herpes simplex virus, Neuroretinitis, Primoinfection, Macular star, Case report

\section{Background}

Herpes simplex viruses (specifically HSV-1 and HSV2) are greatly prevalent. In 2016, a $66.6 \%$ of the world's population aged $15-49$ years were living with HSV type 1 infection and $13.2 \%$ with HSV type 2 . The spectrum of disease includes primary and recurrent infections that causes cutaneous or genital herpes, encephalitis, conjunctivitis, and keratitis [1], establishing a lifelong latent

*Correspondence: berrada.halima7@gmail.com

${ }^{1}$ Centro de Oftalmología Barraquer, Muntaner 314, 08021 Barcelona, Spain

Full list of author information is available at the end of the article infection with reactivations. Other ocular disorders such as acute retinal necrosis syndrome or neuroretinitis [2,3] are rare occurrences for these pathogens. Asymptomatic primary infection is the most frequent form observed in patients with herpes simplex virus (HSV) [1].

We report the case of an isolated unilateral neuroretinitis as manifestation of a primary HSV infection in an immunocompetent adult without encephalitis or other related clinical features. original author(s) and the source, provide a link to the Creative Commons licence, and indicate if changes were made. The images or other third party material in this article are included in the article's Creative Commons licence, unless indicated otherwise in a credit line to the material. If material is not included in the article's Creative Commons licence and your intended use is not permitted by statutory regulation or exceeds the permitted use, you will need to obtain permission directly from the copyright holder. To view a copy of this licence, visit http://creativecommons.org/licenses/by/4.0/. The Creative Commons Public Domain Dedication waiver (http://creativeco mmons.org/publicdomain/zero/1.0/) applies to the data made available in this article, unless otherwise stated in a credit line to the data. 


\section{Case presentation}

A 60-year-old immunocompetent woman with no significant medical nor surgical history presented with sudden scotoma and painless central vision loss in her left eye. Her medical history revealed cataract surgery in both eyes 1 year prior and myocardial infarction 9 months prior to her visit. Best corrected visual acuity (BCVA) was $20 / 20$ in the right eye and $20 / 200$ in the left eye. On general examination, there were no characteristic herpetic skin lesions. On ocular examination, optic disc edema and juxtapapillary hemorrhages in the left eye were detected. There were no other signs of intraocular inflammation and the right eye features were unremarkable.

In view of its characteristics, the first approach was within an ischemic context. Arteritic and non-arteritic anterior ischemic optic neuropathy (AION) needed to be ruled out by analyzing the patient's history, complementary tests, and medical assessments. Arteritic AION was excluded based on normal erythrocyte sedimentation rate and absence of extraocular clinical signs. The possibility of a non-arteritic AION was considered, and close monitoring was maintained.

Two weeks later, the Goldmann visual field exam revealed no abnormality. The left eye fundus revealed an optic disc edema, submacular fluid and a delayed development of a macular star (Fig. 1. A1). The macular optical coherence tomography (OCT) showed a serous retinal detachment (Fig.1 A2).

The macular star observed in the fundus helped to establish a new differential diagnosis that included diseases like hypertensive or radiation-induced retinopathy and secondary or idiopathic neuroretinitis. There was no history of arterial hypertension nor exposure to ionizing radiation. The neuroretinitis path was comprehensively analyzed and clinical and biological examinations were made.

Contact risks, including food habits, recent travel, sexual experience, and animal contacts were thoroughly explored. A detailed physical examination was performed to note sites with rashes or inoculation spots but was unremarkable. Concerning laboratory tests, immune profile, tuberculin skin test and serological evaluation were performed, including Bartonella, Epstein-Barr virus, Rickettsia, Lyme disease, histoplasmosis, syphilis, chlamydia, human immunodeficiency virus, toxoplasmosis, brucellosis, viral hepatitis B and C, HSV-1, and HSV-2. The only clinical abnormality was a positive immunoglobulin M (IgM) for HSV-1, which in absence of any other systemic clinical feature allowed etiological diagnosis.

A treatment regimen with valacyclovir $1 \mathrm{~g}$ every $8 \mathrm{~h}$ was started and we observed a clinical improvement at
2 weeks with a decrease of the symptoms and progressive resolution of the fundus signs (Fig. 1 B1, B2, C1 and $\mathrm{C} 2$ ). After $48 \mathrm{~h}$ of antiviral treatment, oral tapered prednisone regimen was added for 6 weeks and valacyclovir was decreased to $1 \mathrm{~g}$ per day until discontinuation of oral prednisone (length of antiviral treatment of 10 weeks). The treatment was well tolerated and no adverse events occurred. The patient recovered over 3 months without any sign of intraocular inflammation (Fig.1 D1 and D2) and an improvement of BCVA up to 20/25.

\section{Discussion and conclusions}

Neuroretinitis cases have been related to a variety of infectious agents [4]. Other rare pathogens should be considered when more common etiologies such as Bartonella henselae have been excluded. Infectious neuroretinitis in immunosuppressed patients are usually common. However, in immunocompetent patients a few cases with mild systemic signs or symptoms that were resolved with antiviral agents have been reported. Specifically, a previously published report of a 28-year-old male with signs of neuroretinitis, chickenpox and positive titer of immunoglobulin G (IgG) for varicella zoster virus without polymerase chain reaction (PCR) analysis was completely resolved with oral acyclovir [2]. Moreover, a 48-year-old female with neuroretinitis was positive using PCR and IgG positive for both cytomegalovirus and HSV-1 with previous history of flu symptoms was successfully treated with intravenous and intravitreal ganciclovir [3]. Here, we present an unusual case of neuroretinitis in an immunocompetent patient with no other systemic symptoms or signs in a primary HSV infection.

When a patient shows typical manifestations of HSV infection, a clinical diagnosis might be enough. In an immunocompetent patient with atypical manifestations like neuroretinitis, biological examinations could be useful, such as blood tests for specific antibodies or nucleic acid amplifications tests. A PCR test is often a very useful tool to confirm a diagnosis of HSV. It is worth mentioning that, the reliability of a PCR test on ocular fluids has been reported to be lower in immunocompetent than in immunosuppressed patients [5]. Specifically, a negative PCR result cannot reliably rule out the infection in immunocompetent patients but a positive result, certainly, can confirm it. Unfortunately, a PCR test at the acute stage for our patient was not performed, so we based the diagnosis on positive IgM with negative IgG titers for HSV-1. This was also supported by the good response to antiviral treatment, as in the previously reported cases in immunocompetent patients $[2,3]$.

In conclusion, we report a case of isolated neuroretinitis as a primary HSV infection in an immunocompetent patient with resolution and good functional results after 

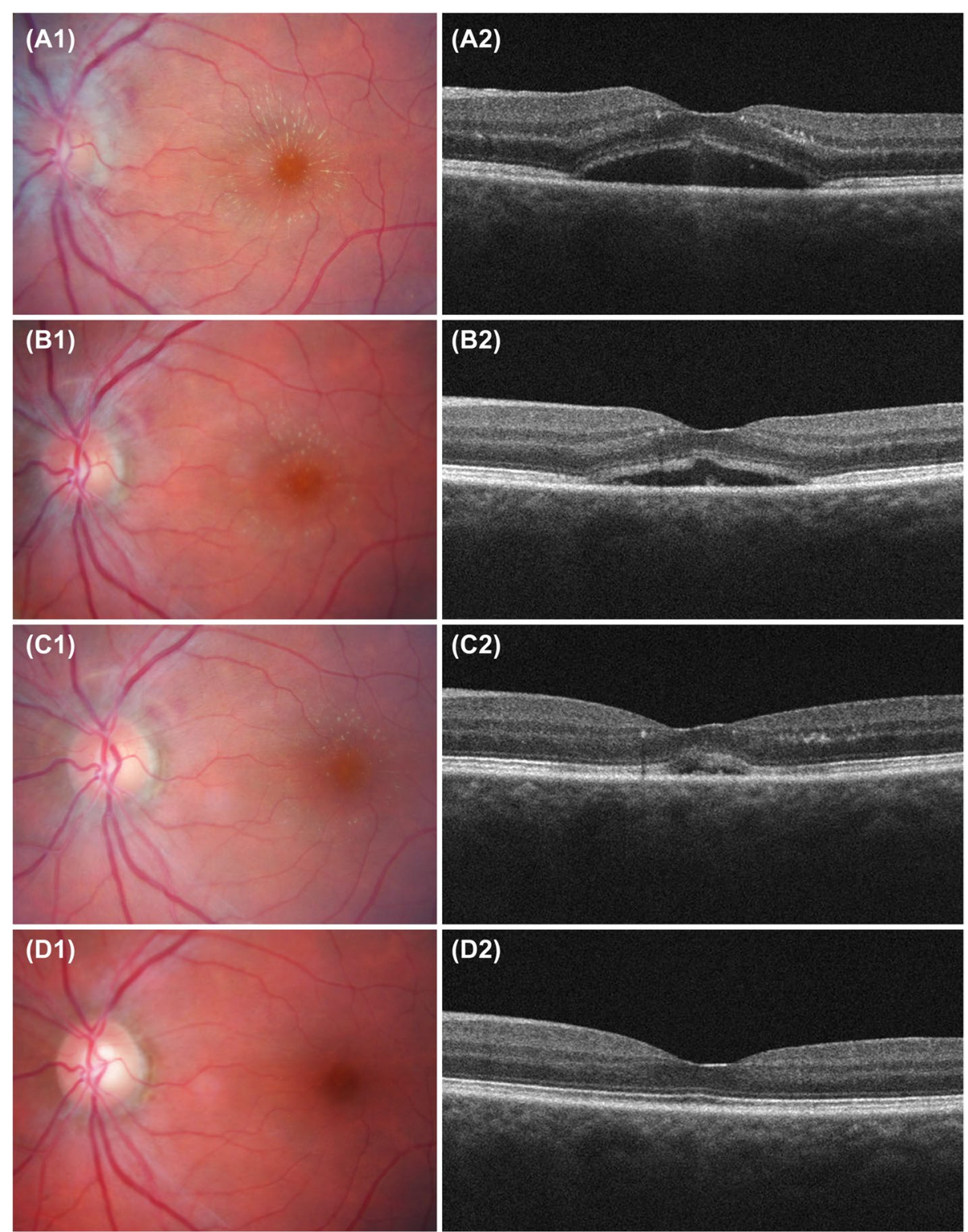

Fig. 1 Color retinography images showing a macular star (A1) and its progressive reduction (B1 at 2 weeks, $\mathbf{C} \mathbf{1}$ at 1 month, and D1 at 3 month). Optical coherence tomography images showing serous retinal detachment (A2), and its progressive resolution (B2 at 2 weeks, C2 at 1 month, and D2 at 3 month)

valacyclovir treatment. Presence of HSV IgM in absence of other laboratory results could be enough evidence to start HSV treatment in immunocompetent patients with a macular star, as an isolated lesion, after ruling out other non-infectious causes, such as arterial hypertension or exposure to ionizing radiation. Rare infectious agents in immunocompetent patients must be considered in the differential diagnosis of neuroretinitis, even if there are no other typical symptoms or signs that could suggest the disease.

\section{Abbreviations}

AION: Anterior ischemic optic neuropathy; BCVA: Best corrected visual acuity; HSV: Herpes simplex virus; HSV-1: herpes simplex virus type 1; HSV-2: herpes simplex virus type 2; IgG: Immunoglobulin G; IgM: Immunoglobulin M; OCT: Optical coherence tomography; PCR: Polymerase chain reaction.

\section{Acknowledgements}

Dr. Michael J. Edel of Centro de Oftalmología Barraquer for the English edition of the manuscript.

\section{Financial disclosure}

The authors have no financial, proprietary or commercial interest in any materials presented herein." was removed. Please check if correct. 


\section{Authors' contributions}

VLR had the conception and design of the study. MJC carried out the clinical management of this patient. HB collected the data and drafted the case report. VLR and HB wrote the manuscript with support from MJC. MJC encouraged VLR and $H B$ to investigate the use and relevance of the reliability of PCR tests on ocular fluids and supervised the findings of this work revising it critically for important intellectual content. All authors provided critical feedback and helped shape the research and manuscript. All authors discussed the results and contributed to the final manuscript. The author(s) read and approved the final manuscript.

\section{Funding}

This research did not receive any specific grant from funding agencies in the public, commercial, or not-for-profit sectors.

\section{Availability of data and materials}

Not applicable.

\section{Declarations}

\section{Ethics approval and consent to participate}

The authors obtained written informed consent to participate from the patient.

\section{Consent for publication}

Written informed consent was obtained from the patient for publication of this Case report and any accompanying images. A copy of the written consent is available for review by the Editor of this journal.

\section{Competing interests}

The authors declare that they have no competing interests.

\section{Author details}

${ }^{1}$ Centro de Oftalmología Barraquer, Muntaner 314, 08021 Barcelona, Spain.

${ }^{2}$ Institut Universitari Barraquer, Universitat Autònoma de Barcelona, Barcelona, Spain.

Received: 4 August 2021 Accepted: 25 January 2022

Published online: 01 February 2022

\section{References}

1. Liesegang TJ. Herpes simplex virus epidemiology and ocular importance. Cornea. 2001;20(1):1-132.

2. Tsao WS, He MS, Tsai RK. Varicella zoster virus-associated neuroretinitis. Taiwan J Ophthalmol. 2015;5:189-91.

3. Thitiwichienlert S, Leeamornsiri S. Combined cytomegalovirus and herpes simplex virus-related Neuroretinitis in an Immunocompetent patient. Korean J Ophthalmol. 2019;33(4):395-6.

4. Purvin V, Sundaram S, Kawasaki A. Neuroretinitis: review of the literature and new observations. J Neuroophthalmol. 2011;31:58-68.

5. Harper TW, Miller D, Schiffman JC, Davis JL. Polymerase chain reaction analysis of aqueous and vitreous specimens in the diagnosis of posterior segment infectious uveitis. Am J Ophthalmol. 2009;147(1):140-147.e2.

\section{Publisher's Note}

Springer Nature remains neutral with regard to jurisdictional claims in published maps and institutional affiliations.

Ready to submit your research? Choose BMC and benefit from:

- fast, convenient online submission

- thorough peer review by experienced researchers in your field

- rapid publication on acceptance

- support for research data, including large and complex data types

- gold Open Access which fosters wider collaboration and increased citations

- maximum visibility for your research: over $100 \mathrm{M}$ website views per year

At BMC, research is always in progress.

Learn more biomedcentral.com/submissions 